\title{
Design Thinking en STEAM
}

\begin{abstract}
Ana Albalat Martínez (aalbala2@xtec.cat) Assessora tècnica docent del servei de formació, innovació $i$ orientació de Secundària del Departament d'Ensenyament.
\end{abstract}

El Design Thinking és una estratègia de pensament creatiu que situa en el centre del procés a l'usuari de la solució a implementar. Donada la seva flexibilitat i facilitat d'adaptació a diferents propostes, al llarg dels últims dos anys ha estat una metodologia utilitzada en el meu dia a dia en l'aula, obtenint bons resultats degut a l'increment de la motivació dels alumnes per la seva participació més activa apropant-los a les STEAM.

Paraules clau: Design Thinking, procés, creativitat, usuari, educació, STEAM.

Design Thinking is a strategy for creative thinking that situates the user in the centre of the solution to be implemented. Because of its flexibility and its easy adaptation to different proposals, this methodology has been used in my school daily life during the two last years. I have obtained good results produced by an increase of students' motivation and active participation, driving them to STEAM areas.

Paraules clau: Design Thinking, process, creativity, user, education, STEAM.

\section{QUÈ ÉS EL DESIGN THINKING?}

El Design Thinking és una estratègia de pensament creatiu que estructura el procés de creació de solucions estimulant la creativitat. Situa en el centre a l'usuari de la solució a implementar, adaptant-lo a les seves necessitats i desitjos. Pot ser aplicat per crear un nou objecte, servei, procés, millora de models existents,...

Algunes de les avantatges del Design Thinking que fan que sigui una bona eina de treball són: Promou el treball en equip, inclusiu, actiu, participatiu, productiu i creatiu. No obstant, requereix, per al bon funcionament, d'un moderador del procés que conegui la metodologia i animi a la participació activa.

Aquesta filosofia ha estat promoguda per Tim Brown, un professor d'enginyeria en la Universitat de Stanford i CEO de la companyia IDEO que realitza serveis de consultoria en innovació. La seva aplicació és tan amplia que en els últims anys aquest concepte s'ha arribat a introduir en el món dels negocis, la tecnologia, l'educació i altres tants sectors, que d'una forma o altra, busquen la innovació. Inclús s'ha fomentat l'ús del pensament de disseny en oficines i equips de treball, com a forma per aconseguir idees i projectes més innovadors i creatius.

Podem estructurar el Design Thinking en multitud de fases, com podrien ser: connectar, comprendre, observar, empatitzar, sintetitzar, planificar, idear, visualitzar, prototipar, testar, implementar i comunicar. No obstant per facilitar el procés i acotar els temps de realització, és sol parlar de 5 fases: empatitzar, definir, idear, prototipar i testar.

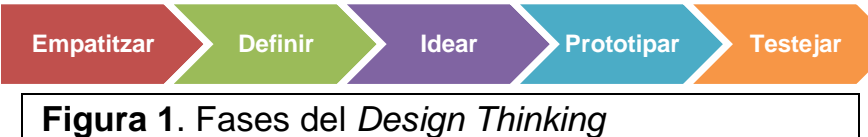

\section{Context}

Previ a l'inici de les fases del Design Thinking cal emmarcar un context de treball. Quan més acotem el context i més petit sigui l'espai de reflexió, menys propostes però més concretes i adients seran les solucions proposades. En canvi, si disposem d'un 
marc ampli les solucions poden ser diverses, infinites i respondre a diferents necessitats ben diferenciades, en aquest cas és requereix un bon moderador de procés.

\section{Empatitzar}

Ens posem en el lloc de l'usuari, per entendre com viu ell/a al voltant d'aquest objecte, servei i/o procés, detectant desitjos i necessitats. Com treballa, utilitza aquesta eina, servei o procés? Com es sent quan la utilitza? Quines son les seves pors i frustracions?, que seran les barreres en el nostre disseny. I quines les seves motivacions i hàbits? que faran viable i fàcil d'adaptar la nostra solució. Quan més coneixem a l'usuari més s'adaptarà la nostra solució a les seves expectatives, i d'aquesta forma donarem una resposta més adequada.

Cal recordar que el comportament i hàbits humans es distribueixen en una campana de Gauss, en la que és important no oblidar les minories i quedar-nos sols en la corrent principal, considerant també la població més activa i la sedentària.

Caldrà focalitzar si es necessari, dintre del nostre usuari potencial, aquell d'una tipologia en concret. Així, per exemple, en el cas d'intentar generar un producte que respongui a la productivitat d'uns treballadors d'una empresa determinada, el que ens interessa observar no és el treballador en si, si no els tres subconjunts, el no productiu, el intermedi i el molt productiu, de forma, que es pugui aprendre i prendre mesures de l'extracció de maneres de procedir, eines utilitzades, aprenentatges previs, equip de treball, cooperació...

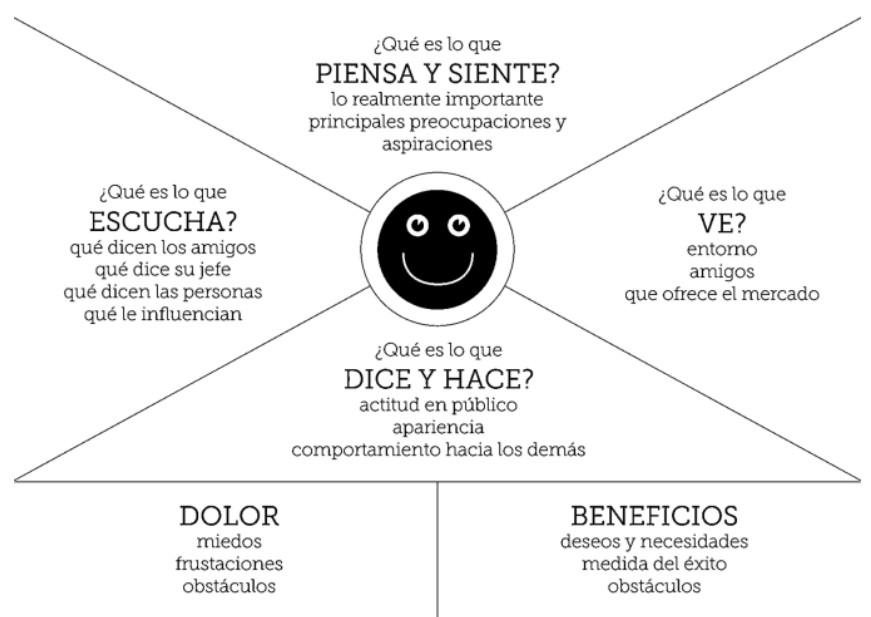

Figura 2. Mapa d'empatia per poder situar-nos en la pell de l'usuari, i compartir quin és el seu punt de vista i experiència al voltant del producte o servei al que ens enfrontem.
L'eina més coneguda per a aquesta fase és el mapa d'empatia (figura 2). No obstant en funció del que volem descobrir, podem crear les nostres pròpies eines.

\section{Definir}

Totes les idees recollides en la fase d'empatia, s'organitzen. Podem realitzar diferents agrupacions en funció de les necessitats que són semblants, aspectes comuns que necessiten solucions d'un mateix tipus, i podem desagrupar i agrupar tants cops com sigui necessari. L'objectiu és anar creant patrons de solució amb una llista d'aspectes a controlar. Per exemple, en el cas de crear un repte de disseny d'un element per suport i treball a casa, podríem parlar d'aspectes com ara materials, funcions, dimensions, propietats... Són idees concretes, es tractaria de crear els principis de disseny convertibles en la propera fase en idees de disseny. De idees concretes i generals: es va conformant un "brainstorming" en el qual es llencen un gran nombre de conceptes relacionats amb l'ús del producte o servei. Aquests queden recollits sobre un paper pel seu posterior anàlisi, filtratge i selecció. La finalitat d'aquesta fase es definir i acotar la temàtica concreta a tractar.

\section{Idear}

Partint dels conceptes mencionats i anotats, seleccionem aquells que resulten de major importància i els desenvolupem més a fons tractant d'arribar a idees més concretes.

Aquesta fase als tecnòlegs els recordarà a la fase del procés tecnològic en la que cal crear diferents possibles solucions i finalment quedar-nos amb una. Aquesta selecció es fa seguint els criteris i paraules extretes de la fase d'empatitzar, com a requeriments, i depenent el material i recursos necessaris i disponibles.

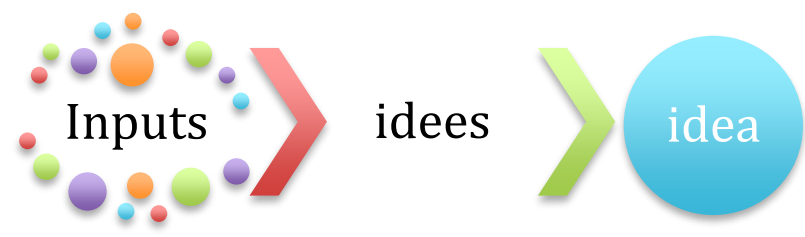

Figura 3. Fases per idear.

Com podeu observar, aquest procés és similar a "Selecció de la millor solució: ha arribat l'hora de decidir. Per escollir el producte més adequat s'han d'analitzar diversos factors (resposta al requeriment, 
possibilitats de realització amb el material i equipament disponible, originalitat del producte, cost, estètica, impacte ambiental de la proposta...) i avaluar els pros i contres de cada idea" (extret de: http://www.edu365.cat/batxillerat/comfer/projecte/ ), però centrat amb el requeriments de l'usuari.

\section{Prototipar}

En base a aquestes idees elaborem un prototip final que resumeix tot el que és la idea, una innovació que respon a les necessitats de l'usuari. A l'hora d'elaborar un prototip podem desenvolupar un enginy més conceptual o bé desenvolupar un model semblant a la implementació final, tot dependrà de la solució que es tracti i el temps i recursos disponibles en el moment del prototipatge.

Si es tracta d'un treball més d'anàlisis de necessitats en que no disposem de molt de temps per desenvolupar el prototip, realitzarem una conceptualització que ens permeti comunicar visualment a l'usuari la nostra proposta en la fase següent. En el cas de tenir molt grups realitzant aquesta tasca de prototipar, podem disposar d'un espai tipus Tinkering, on l'usuari pot utilitzar els elements per expressar conceptes.

Si la solució s'encamina a un resultat tecnològic com pot ser el desenvolupament d'una app, en el prototipatge serà necessari crear un wireframe de les pantalles, a mode d'esbós o bé programar una versió beta de l'app, que podríem programar amb eines com Applnventor. Si es tracta d'un projecte en el que tenim suficient temps i recursos, i respon a les necessitats del producte o servei necessari, podem incorporar el fenomen maker a aquesta fase.
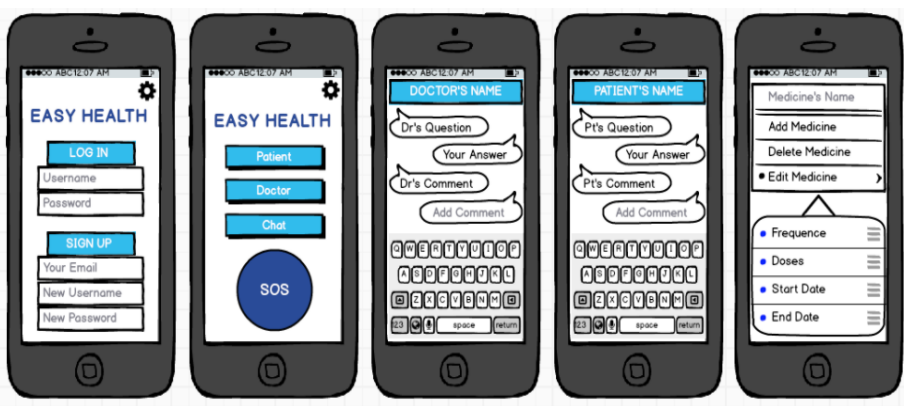

Figura 4. Wireframe en Balsamiq de l'App d'un dels equips de Impulsem la informàtica 4rt d'ESO.

\section{Testejar}

L'objectiu d'aquesta fase és valorar l'experiència d'usuari amb el producte dissenyat. És necessari mostrar el resultat del prototipatge i veure com respon l'usuari. Si el prototipatge és més de caire conceptual, possiblement requereixi d'una explicació complementaria. No obstant, és important no marcar la resposta de l'usuari, deixar fer i veure com reacciona, sense donar moltes explicacions del funcionament que ell espera amb aquesta solució. Així, possiblement extraurem conclusions que ens portaran a propostes de millora i refinament de la resposta. Buscarem, per tant, la interacció de l'usuari amb el producte o servei, i analitzarem conjuntament el resultat, tant l'equip de treball com l'usuari potencial, que en algun dels casos pot coincidir, tractant d'aconseguir noves solucions i millores per millorar l'experiència d'usuari.

\section{EXPERIÈNCIES D'AULA AMB DESIGN THINKING}

A continuació hi ha un recull d'experiències d'aplicació del Design Thinking a l'aula, desenvolupades en els darrers anys al INS Ernest Lluch de Barcelona. S'ha escollit cadascuna d'aquestes experiències donada la seva diversitat i flexibilitat per la seva adaptació en l'aplicació: treballs de recerca, projectes, taller, paral-lelisme en altres metodologies... i facilitat d'aplicació a les aules i la flexibilitat per adaptar-les a diferents matèries.

\section{Primera experiència: Invent per millorar necessitats quotidianes}

Un alumne de treball de recerca tenia molt clar que volia dissenyar i programar algun aparell. Per la tutorització del treball vaig orientar-lo mitjançant un procés de Design Thinking per detectar necessitats quotidianes del ser humà en el dia a dia. Després de realitzar moltes enquestes va extreure un problema comú i quotidià: totes les persones enquestades van coincidir en una mateixa frustració, els resultava molt molest quan se li mullava la roba estesa. Així, va centrar el seu estudi en desenvolupar algun enginy que soluciona aquest problema. El resultat del seu treball va ser el disseny i implementació d'un mecanisme que detecta els paràmetres de temperatura i humitat mitjançant uns sensors (Figura 5). Amb aquests paràmetres activa uns servos dels quals depèn el moviment d'un tendal que cobrirà i descobrirà l'estenedor.

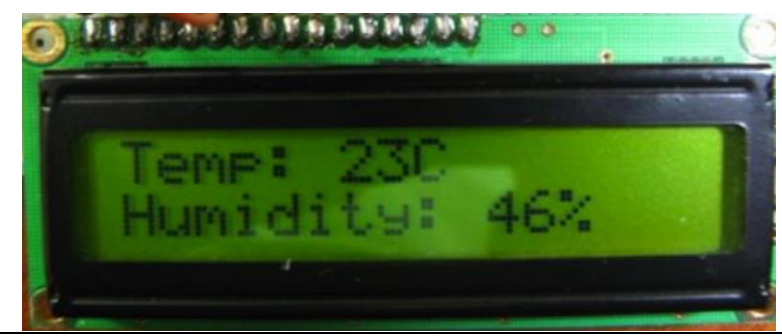

Figura 5. Pantalla LCD que mostra els valors que detecten els sensors. 
L'invent es complementa amb la instal-lació d'una pantalla LCD que mostra els valors i serveix d'estació meteorològica, donat que els usuaris van coincidir en el fet que els agradava conèixer quina era la temperatura ambiental.

\section{Segona experiència: Collaborative Design for a Smart people}

En aquest cas és interessant destacar la fase d'empatia. Aquesta activitat va ser treballada en un grup d'unes 14 persones de 4rt d'ESO, junts vam crear una dinàmica de reflexió basada en el Design Thinking, on una de les primeres fases va tenir gran importància. Es van penjar en el passadís del centre uns grans fulls blancs, amb preguntes com:

a) Què és per tu l'institut?

b) Què és per tu l'educació?

c) Què és per tu la ciència?

d) Què és per tu la tecnologia?

e) Què són per tu les matemàtiques?

f) Què són per tu els projectes?

A partir d'aquest desplegament, els alumnes de tot el centre, aproximadament 700 , tenien la possibilitat durant una setmana, d'aportar una paraula. Junts vam formar un gran mapa d'empatia, que amb l'equip impulsor vam anar desxifrant i agrupant per desencaminar en les següents fases del Design Thinking. Les propostes que van sorgir d'aquest procés van ser:

a) Aprendre coses pràctiques del dia a dia amb tallers que imparteixen els pares: Cuina, comptabilitat, drets...

b) Experts de fora del centre per aprendre coses complicades.

c) Classes de primers auxilis.

d) Crear partits polítics de centre amb fulls de ruta, en els quals qui surt guanyador té representants al consell escolar (La diferència en l'actual sistema, seria que el representant del consell escolar, té un equip de persones de tots els nivells de l'ESO i batxillerat que li ajuden al llarg del seu mandat i que realitzaran accions al centre).

Un dels punts forts d'aquesta activitat va ser l'apoderament de l'alumnat, la participació ciutadana, i el fet que les solucions aportades pels alumnes eren propostes competencials per tractar l'àmbit científic-tecnològic que van desencaminar en propostes del professorat a l'aula.

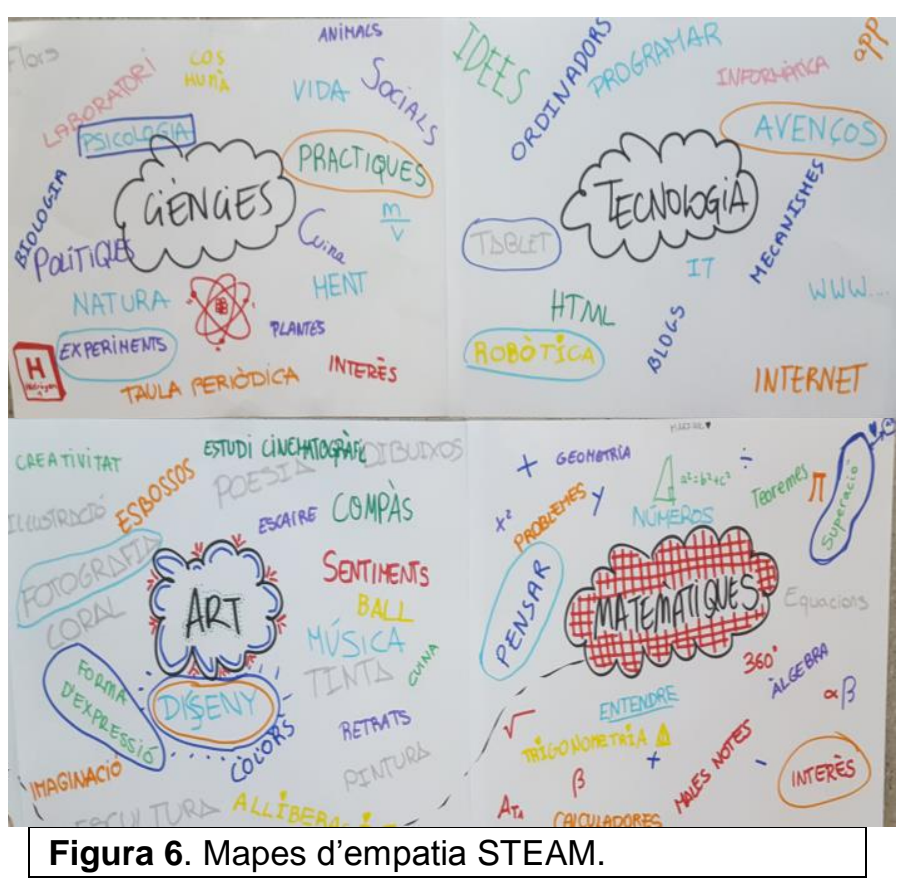

\section{Tercera experiència: El professional del futur}

Aquest taller es va realitzar en el nostre centre en una sessió d'un sol dia, amb alumnat d'una escola francesa i amb els nostres alumnes, un grup d'aproximadament 50 persones, dintre del marc de l'Erasmus+ Collaborative design for smart pupils, i l'objectiu era dinamitzar una activitat per poder compartir una tasca comú, amb l'afegit de la dificultat de comunicar-se i amb un mateix objectiu comú idear i/o pensar el professional del futur. Va donar peu a la reflexió per poder saber quins aprenentatges i competències devien desenvolupar.

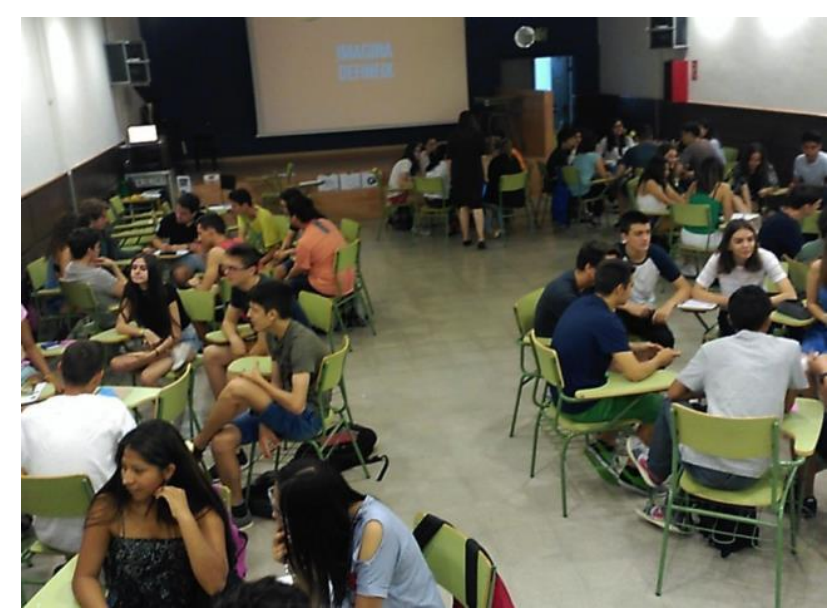

Figura 7. Alumnes treballant en equips heterogenis, multidisciplinaris i multiculturals. 


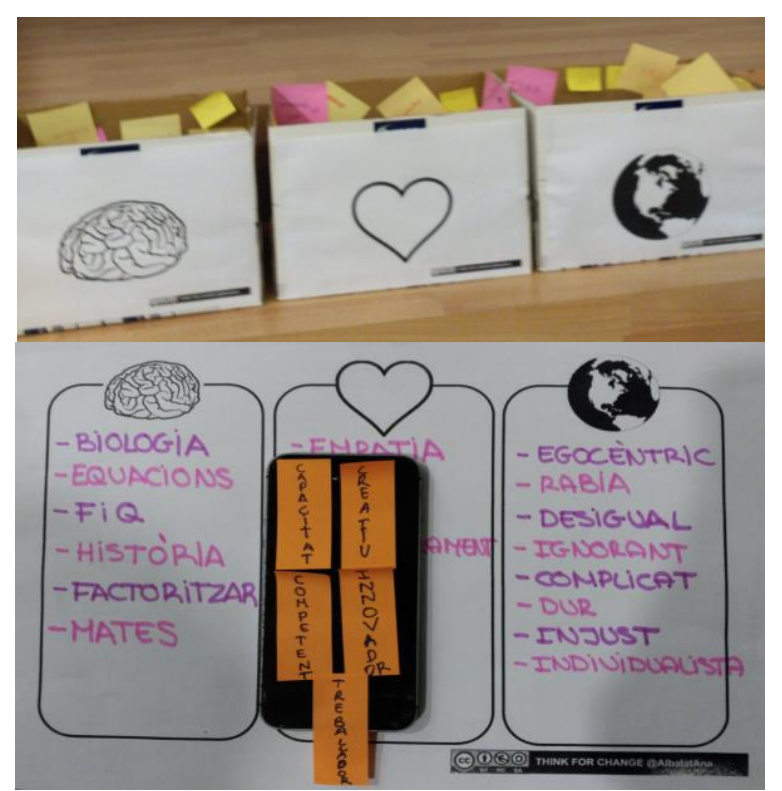

Figura 8. Es va dissenyar un canvas per recollir coneixements requerits, emocions i actituds necessàries i visió del món. Posteriorment es va fer un buidatge dels canvas, agrupament d'aspectes i reflexió en amb tots els equips.

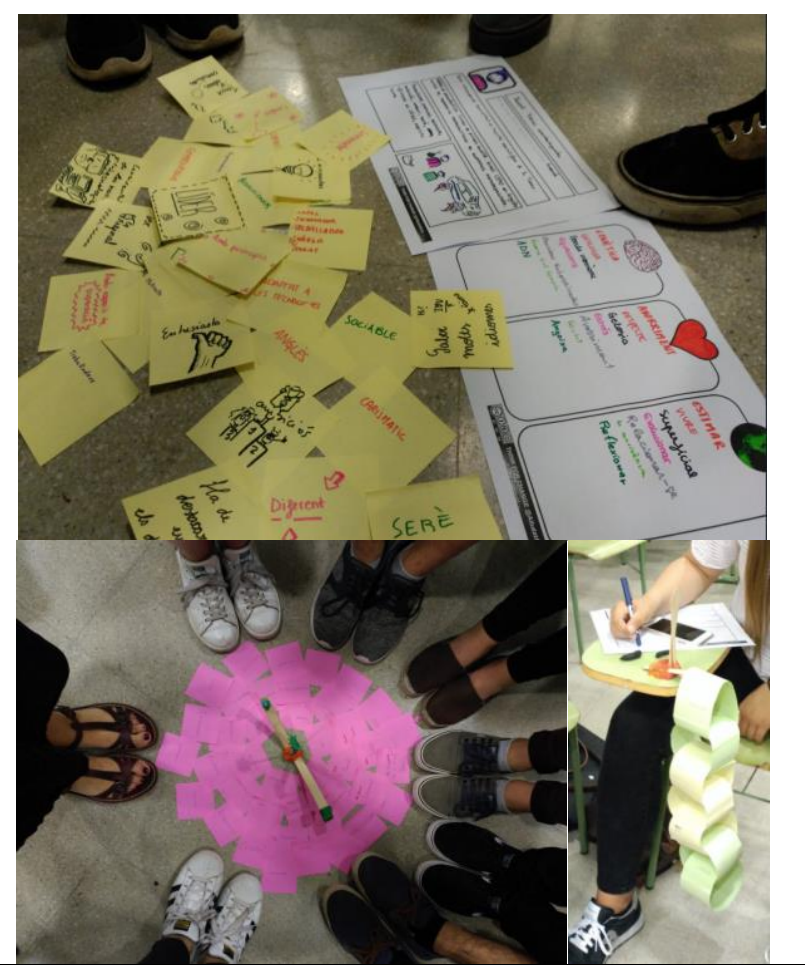

Figura 10. Diferents tipus de prototipatge: amb composició de les idees claus i acompanyat de visual thinking (a dalt), que representa les idees d'equilibri i de composició com una necessitat de globalitat (a baix, a l'esquerra) i que conceptualitza el futur com una cadena de creixement en valors $i$ aprenentatges (a baix, a la dreta).

\section{Quarta experiència: 08015. Un projecte que canviarà el barri}

Aquest és un bon exemple per entendre el concepte de context abans mencionat. En aquest cas el context prèviament definit per portar a terme el projecte en el que seguiríem les fases del Design Thinking, serà "el nostre barri" en concret voldrem saber les necessitats que tenen els nostres veïns per pensar conjuntament solucions encaminades a convertir el nostre barri en un Smart barri. Al definir com a context el nostre barri, automàticament tenim concretat l'usuari. El target al que adrecem la nostra recerca és el veïnat del codi postal 08015 . El veïnat està compost per persones de diferents edats, necessitats, estudis, situacions econòmiques... i és el primer pas a tenir en compte a l'hora de segmentar i agrupar les necessitats de diferents tipologies d'usuaris.

Objectius del projecte anual:

a) Millorar la capacitat de treball en equip, de gestió i de resolució.

b) Despertar la curiositat, l'observació, l'esperit crític i la contribució per canviar el món.

c) Enriquir els alumnes amb els coneixements tecnològics necessaris a l'hora de resoldre problemes a partir de la recerca d'informació.

d) Incrementar la competència digital de l'alumne.

e) Millorar la competència comunicativa oral i escrita en diferents idiomes i així com la comunicació audiovisual amb l'ús d'eines TIC.

f) Apropar les noies a vocacions STEM, en concret a la tecnologia.

El procés de treball enfocat als alumnes és:

1. Formeu un equip.

2. Detecteu les necessitats del barri.

3. Cerqueu una solució.

4. Porteu a terme el projecte per satisfer-les.

5. Comuniqueu els resultats.

Procés de treball orientat pel professorat.

1. Empatitzar: Enquestes a la població per detecció de necessitats. 20 alumnes preguntant a 10 persones, dos de cadascuna de les 5 franges d'edat diferents.

2. Definir: Agrupaments diferents per extreure informació de la resposta dels usuaris, activitats d'estímul de la creativitat per reinventar espais...

3. Idear crear propostes de projectes: Cada alumnes enregistra un vídeo amb la seva proposta, creen equips que s'acullen a projectes, finalment és selecciones i fusionen propostes que es plasmen en en un total de 30 projectes 
diferents que responen a temes de sostenibilitat, mobilitat, pobresa energètica, gènere... lliguem aquestes propostes amb els ODS 2020 de la UNESCO

4. Prototipar: els alumnes creen un model conceptual, vídeo informatiu o publicitari, pòster... per mostrar la seva proposta.

5. Testatge: Mostren els resultats als companys i familiars, coavaluen i milloren les propostes

6. Implementació de la proposta.

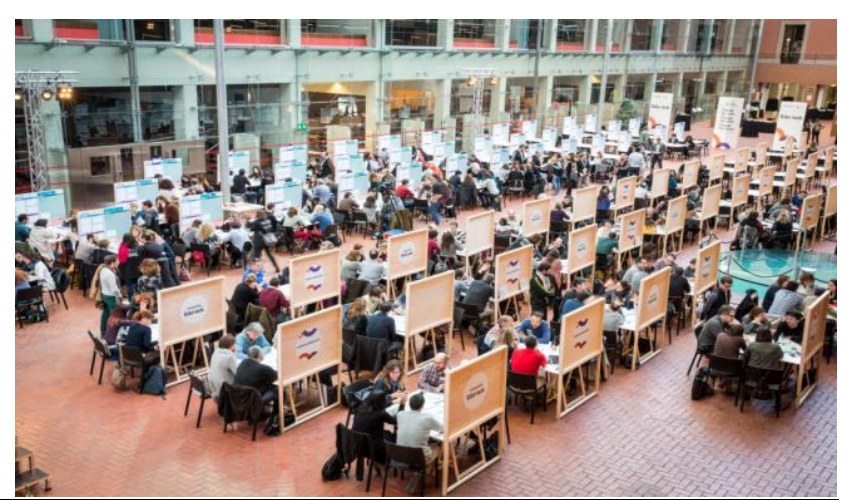

Figura 13. Els membres de diferents equips participant en equips treballant en la seu de Barcelona en la UPF.

\section{Cinquena experiència: Eduhack}

En aquest cas es tracta d'un projecte promogut pel Departament d'Ensenyament junt a GSMA dintre del projecte mSchools. L'objectiu de l'Eduhack és seguir les fases del Design Thinking per la generació de projectes educatius.

\section{RECURSOS}

Projecte "Explica fora de l'Aula": https://drive.google.com/file/d/0B-5y7UkJpGANbFFnUIU2eURtV00/view

Vídeo ITworldEdu9. 08015:un projecte que canviarà el barri: https://www.youtube.com/watch?v=7omRDJrkUm4\&t=2990s

Eduhack i Design Thinking: http://projectes.xtec.cat/eduhack/design-thinking/

Collaborative design for smart pupils: http://punttic.gencat.cat/etiqueta/smart-pupils 